\title{
基礎杭の摩擦支持力について
}

准員西田義親*

\section{ON THE SUPPORTING POWER OF A FOUNDATION PILE BY FRICTION}

(Trans. of JSCE March 1952)

Yoshichika Nishida, C.E. Assoc. Member.

Synopsis There are many formulas on calculating the supporting power of foundation piles, but in those formulas the influence by piles to the stress distribution in the earth-body is not taken into consideration. And so the writer has theoretically studied the supporting power of a pile by friction in statics. As the result of study the writer has been able to bring out the base of calculation clearly on a friction-pile.

要旨 基礎杭の支持力式としては静力学的な計算式によるるのが，比較的根本的な誤りが少ないとされ種々の 公式が提案されているが，何れる机の存在による地中応力への影響が考虑されていない。著者はこの点にかん がみ，杭支持力のうち周面摩擦によるもののみをとりあげて理論的に検討し，その根拠を明らかにした。

1. 基 本 式

今，地表面水平の半無限体の地中に杭が徐直に打ち込まれてむるるのとする。地 表面杭中心を原点にとり鉛直（杭軸）の地中方向にz糨をとる円筒座標 $r, t ， z$ ， を用いる(図一-1 参照)。然るときは，基本の釣合の微分方程式は，杭軸に関して 対称の関係より次の 2 つになる。

$$
\begin{aligned}
& 2(m-1)\left\{\frac{\partial^{2} u}{\partial r^{2}}+\frac{\partial}{\partial r}\left(\frac{u}{r}\right)\right\}+(n-2) \frac{\partial^{2} u}{\partial z^{2}}+m \frac{\partial^{2} w}{\partial r \partial z}=0 \\
& m\left(\frac{\partial^{2} u}{\partial z \partial r}+\frac{1}{r} \frac{\partial u}{\partial z}\right)+(m-2)\left(\frac{\partial^{2} w}{\partial r^{2}}+\frac{1}{r} \frac{\partial w}{\partial r}\right)+2(m-1) \frac{\partial^{2} w}{\partial z^{2}}+\rho_{s}=0
\end{aligned}
$$

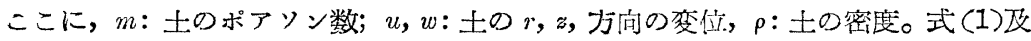
び式(2)をそれそれれ，r，で微分し，その阙式より $\partial w / \partial r$ 又は $\partial u / \partial z$ を消去すれば

この解は1)

$$
\left(\frac{\partial}{\partial r}-\frac{1}{r} \frac{\partial}{\partial r} r+\frac{\partial^{2}}{\partial z^{2}}\right)^{2} y=0, \quad y \equiv \frac{\partial u}{\partial z} \text { 又は } \frac{\partial w}{\partial r}
$$

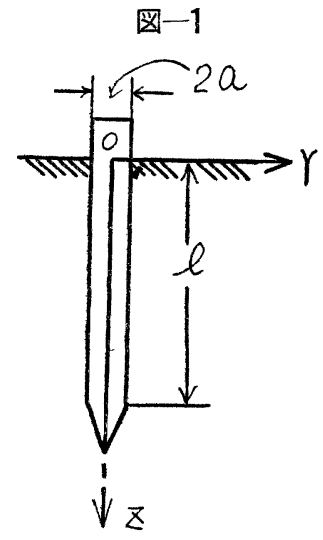

$$
\begin{aligned}
y^{2}= & \Sigma\left[A \cos (k z+\alpha) I_{1}(k r)+B \cos (k z+\beta) K_{1}(k r)+C r \cos (k z+\gamma) I_{0}(k r)\right. \\
& \left.+D r \cos (k i+\delta) K_{0}(k r)+F z \cos (k z+\eta) I_{1}(k r)+G z \cos (k r+\theta) K_{1}(k r)\right]
\end{aligned}
$$

ここに, $A, B, C, D, F^{\prime}, G, \alpha, \beta, \gamma, \delta, \eta, \theta$, は積分常数, $I_{1}(k r), I_{0}(k r), K_{1}(k r)$, $K_{0}(k r)$ は $k$ をパラメータとし $r$ を变数とするべッセル函数で $I_{1}, K_{0}$, 等と記昘す る。従つて

$$
\begin{aligned}
\frac{\partial u}{\partial z=} & \Sigma\left[A \cos (k z+\alpha) I_{1}+B \cos (k z+\beta) K_{1}\right. \\
& +C r \cos (k z+\gamma) I_{0}+D r \cos (k z+\delta) K_{0} \\
& \left.+F^{\prime} z \cos (k z+\eta) I_{1}+G z \cos (k z+\theta) K_{1}\right] \cdots \\
\frac{\partial w}{\partial r}= & \Sigma\left[A^{\prime} \cos \left(k z+\alpha^{\prime}\right) I_{1}+B^{\prime} \cos \left(k z+\beta^{\prime}\right) K_{1}\right. \\
& +C^{\prime} r \cos \left(k z+\gamma^{\prime}\right) I_{0}+D^{\prime} r \cos \left(k z+\delta^{\prime}\right) K_{0} \\
& \left.+H^{\prime} z \cos \left(k z+\eta^{\prime}\right) I_{1}+G^{\prime} z \cos \left(k z+\theta^{\prime}\right) K_{1}\right]
\end{aligned}
$$

今, 図一2 の如く $r$ 軸に対称に反対方向に重力の作用寸る 2 つ半無限体を重ね ると，wはの奇函数であり，uはzの偶函数であることが分るから，この性質 より次のように扔か朴はらない。

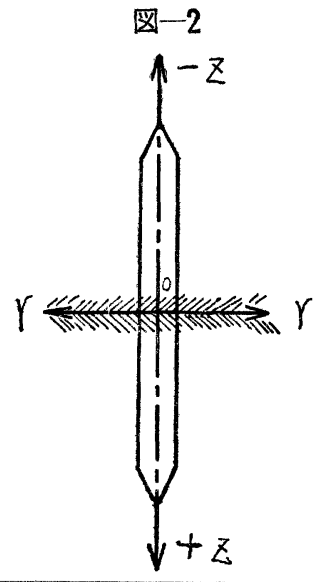

* 金沢大学講師, 工.学部土木教室 


$$
\begin{aligned}
& \alpha=\beta=\gamma=\delta=\alpha^{\prime}=\beta^{\prime}=\gamma^{\prime}=\delta^{\prime}=\frac{\pi}{2} \\
& \theta=\theta^{\prime}=0
\end{aligned}
$$

\section{2. 境界条件}

さて地中に杭が打ら込まれた場合，杭から相当に離れた所では，杭による变形の影響は消失寸る管である。

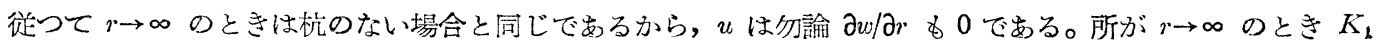
$\rightarrow 0, r K_{0} \rightarrow 0$ となるが， $I_{1} \rightarrow \infty, I_{0} \rightarrow \infty$ となるから，実際の事情に適合寸るには次の如く抢かねはならない。

$$
A=C=F^{\circ}=A^{\prime}=C^{\prime}=F^{\prime \prime}=0
$$

式 (7)，(8)，(9) を式 (5)，(6) に代入すると

$$
\begin{aligned}
& \frac{\partial u}{\partial z}=\Sigma\left[-B \sin k z K_{1}-D r \sin k z K_{0}+G z \cos k z K_{1}\right] \ldots \\
& \frac{\partial w}{\partial r}=\Sigma\left[-B^{\prime} \sin k z K_{1}-D^{\prime} r \sin k z K_{0}+G^{\prime} z \cos k z K_{1}\right]
\end{aligned}
$$

所が土を一応弾性体と考えて検討しているのであるが，この土に比べて杭は相当の岡度をるつ岡性体とみなす

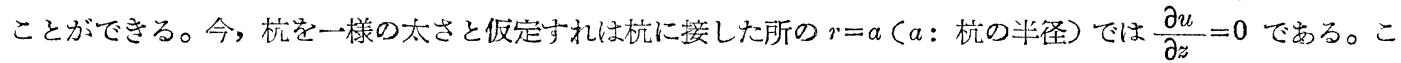
れが $z$ の如何にかかわらず成立寸るためには式 (10) より次のようになる。

$$
\begin{aligned}
& G=0 \\
& D=-\frac{B}{a} \frac{K_{1} a}{K_{0 a}}
\end{aligned}
$$

但し， $K_{1 a} ， K_{0 a}$ はそれれそれ $r=a$ のときの $K_{1} ， K_{0}$ である。式 (10)，(11) をそれぞれ積分すると

$$
\begin{aligned}
& u=f(r)+\Sigma\left[B K_{1}-\frac{1}{k} \cos k z+D r K_{0} \frac{1}{k} \cos k z\right] \\
& w=g(z)+\Sigma\left[D^{\prime} K_{0} \frac{1}{k} \sin k z+D^{\prime} \cdot K_{1} \frac{1}{k} \sin k z-G^{\prime} z \cos k z \frac{1}{k} K_{0}\right]
\end{aligned}
$$

さて杭の存在しない半無限体の地中の鉊直少向の垂直応力 $\sigma_{z}$ は深さに比例するすのとし， $\sigma_{z}=\rho z$ と抢くこと ができる。従つてこのときの鉊直方向の垂直霆 $\varepsilon_{z}$ は $\varepsilon_{z}=\frac{\partial w}{\partial z}=\frac{(m-2)(m+1)}{E m(m-1)} \rho z$ となる。杭が存在するとき

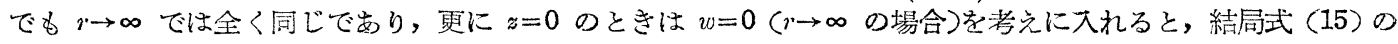
$g(z)$ は次のようになる。

$$
g(z)=\frac{(m-2)(m+1)}{\operatorname{Em}(m-1)} \frac{1}{2} \rho z^{2}
$$

次に剪断応力と

$$
\begin{aligned}
\tau & =\frac{1}{2} \frac{m E}{m+1}\left(\frac{\partial u}{\partial z}+\frac{\partial w}{\partial r}\right) \\
\sigma_{z} & =\frac{m E}{(m+1)(m-2)}\left(\frac{\partial u}{\partial r}+\frac{u}{r}\right)+\frac{m(m-1) E}{(m+1)(m-2)} \frac{\partial w}{\partial z}
\end{aligned}
$$

但し上の各式のちちの $E$ は土のヤング係数である。

地表に於ては剪断応力も $z$ 方向の垂直応力子共に作用しない。式 (14)，(15)，(16）を式 (17) に入礼てみ ると $z=0$ で $\tau=0$ であることは明らかである。従つて次に, $z=0$ で $\sigma_{z}=0$ であるために, 式 (14), (15),

(16) を式 (18) に代入して，次の関係を充さねはななない。

$$
\begin{aligned}
& (m-1) \Sigma\left[B^{\prime} K_{0}+D^{\prime} r \cdot K_{1}-G^{\prime} K_{0} \frac{1}{k}\right]+\frac{f(r)}{r}+\Sigma\left[B \frac{K_{1}}{r} \frac{1}{k}+D K_{0} \frac{1}{k}\right] \\
& +\frac{\partial f(r)}{\partial r}+\Sigma\left[-B\left(\frac{K_{1}}{r} \frac{1}{k}+K_{0}\right)+D K_{0} \frac{1}{k}-D r \cdot K_{1}\right]=0
\end{aligned}
$$

この式を積分して $f(r)$ を求めると

$$
\begin{aligned}
& f(r)=\Sigma\left[K_{1}\left\{-\frac{B}{k}-4 \frac{D}{k^{2}}+(m-1) \frac{B^{\prime}}{k}-(n-1) \frac{G^{\prime}}{k^{2}}+(m-1) D^{\prime} \frac{2}{k^{2}}\right\}\right. \\
& \left.+r K_{0}\left\{\frac{D}{k}+(m-1) D^{\prime}-\frac{1}{k}\right\}\right]+\frac{C_{*}}{r}
\end{aligned}
$$

所が杭を地中に打ち込むと，土は側方に圧して排除せられ，すぐに降伏状態に達して塑性状態になる。従つて $r=a$ で $u=0$ である。この関係を式 (20) に代入すると積分常数 $C_{*}$ が定まる。式 (13)，(14), (20)より 


$$
\begin{aligned}
& { }^{\prime} U_{*}=\Sigma\left[a K_{1} a\left\{\frac{B}{k}+4 \frac{D}{k^{2}}-(m-1) \frac{B^{\prime}}{k}+(m-1) \frac{G^{\prime}}{k^{2}}-(m-1) D^{\prime} \frac{2}{k^{2}}\right\}\right. \\
& \left.-a^{2} K_{0 a}\left\{\frac{D}{k}+(m-1) \frac{D^{\prime}}{k}\right\}\right]
\end{aligned}
$$

式 (21) を式 (20) に代大寸れば式 (14) の $f(r)$ が定まる。

以上の結果より未知の係数は $B, B^{\prime}, D^{\prime}, G^{\prime}$ の 4 個のみとなる。

次に杭周面に作用する剪断応力と半径 $r$ 方向の垂直応力 $\sigma_{r}$ との比は, 杭と土との最大摩擦係数 $\mu$ を超え得 ないのである。即ち

$$
r=a \text { で } \quad \tau \leqq \mu \sigma_{r}
$$

$\tau=\mu \sigma r$ なる等式が杭周辺の何れの点に生じるかは明らかでない。然しながら杭にかかる荷重が増大寸ると， 最初に杭周面の或る1点にて， $\tau=\mu \sigma r$ なる関係が成立するであろう。更に載荷重が増加すると, 杭周面に於て $\tau=\mu \sigma_{r}$ なる関係の成立する範国が増してくる。而して杭が将に滑動せんとする瞬閒には杭周面全体にわたつて 上述の等号が成立寸る筈である。但し上にのべた考察は杭と土との粘着力を無視するものとしている。以上の考 えより

$$
\begin{aligned}
\sigma_{r} & =\frac{m(m-1) E}{(m+1)(m-2)} \frac{\partial u}{\partial r}+\frac{m E}{(m+1)(m-2)}\left(\frac{u}{r}+\frac{\partial w}{\partial z}\right) \\
\tau & =\frac{1}{2} \frac{m E}{m+1}\left(\frac{\partial w}{\partial r}+\frac{\partial u}{\partial z}\right)
\end{aligned}
$$

$r=a$ で $u=0, \frac{\partial u}{\partial z}=0$ を考えに入れ，式 (14)，(15)，(16) を代入して $\tau=\mu \sigma_{r}$ とおくと

$$
\begin{aligned}
& \Sigma \frac{1}{2}\left[-B^{\prime} K_{1 a} \sin k z-D^{\prime} a K_{0 a} \sin k z+G^{\prime} K_{1 a} z \cos k z\right] \\
& =\sum \mu \frac{m-1}{m-2}\left[\frac{\partial f(a)}{\partial r}-B\left(\frac{K_{1 a}}{a k}+K_{0 a}\right) \cos k z+D\left(\frac{K_{0 a}}{k}-a K_{1 a}\right) \cos k z\right] \\
& +\mu \frac{(m+1)}{\operatorname{Em}(m-1)} \rho z+\sum \frac{\mu}{m-2}\left[\left(B^{\prime} K_{0 a}+D^{\prime} a K_{1 a}-G^{\prime} \frac{K_{0 a}}{k}\right) \cos k z+G^{\prime} z \sin k z K_{0 a}\right]
\end{aligned}
$$

今上式の右辺第 2 項をフーリエーの級数に展開すると, 杭長を $l$ として,

$$
\mu \rho \frac{m+1}{\operatorname{Em}(m-1)} z=\mu \rho \frac{(m+1)}{\operatorname{Em}(m-1)}\left(\frac{8 l}{\pi^{2}} \sum_{n=0}^{\infty} \frac{(-1)^{n}}{(n=0,1,2,3, \cdots \cdots \cdots)(0 \leqq}\right)^{2} \sin \frac{2 n+1}{l} \frac{\pi}{2} z
$$

式（26）を式（25）に代大して整理すると

$$
\begin{aligned}
& \sum_{0}^{\infty}\left[\frac{1}{2}\left(B^{\prime} K_{1 a}+D^{\prime} a K_{0 a}\right) \sin k z-\frac{1}{2} G^{\prime} K_{1 a} z \cos k z+\mu \frac{m-1}{m-2} \frac{\partial f(a)}{\partial r}-\left\{B\left(\frac{K_{1 a}}{a k}+K_{0 a}\right)\right.\right. \\
& \left.-D\left(\frac{K_{0 a}}{k}-a K_{1 a}\right)\right\} \mu \frac{m-1}{m-2} \cos k z+\mu \rho \frac{(m+1)}{E m(m-1)} \frac{8 l}{\pi^{2}} \frac{(-1)^{n}}{(2 n+1)^{2}} \sin \frac{2 n+1}{l} \frac{\pi}{2} z \\
& \left.+\left(B^{\prime} K_{0 a}+D^{\prime} a K_{1 a}-G^{\prime} \frac{K_{0 a}}{k}\right) \frac{\mu}{m-2} \cos k z+G^{\prime} K_{0 a} \frac{{ }^{\prime} \mu}{m-2} z \sin k z\right]=0
\end{aligned}
$$

式 (27) が z の如何にかかわらず常に成立するためには，次の如く抢か㸚ばならない。

$$
\begin{aligned}
& k=\frac{2 n+1}{2} \frac{\pi}{l} \\
& G^{\prime}=0 \\
& \frac{1}{2}\left(B^{\prime} K_{1 a}+D^{\prime} a K_{0 a}\right)+\mu \rho \frac{m+1}{\operatorname{Em}(m-1)} \frac{8 l}{\pi^{2}} \frac{(-1)^{n}}{(2 n+1)^{2}}=0 \\
& \left.\frac{\partial f(r)}{\partial r}\right|_{r=\pi}=0 \\
& (n-1)\left\{D\left(\frac{K_{0 a}}{k}-a K_{1 a}\right)-B\left(\frac{K_{1 a}}{a k}+K_{0 a}\right)\right\}+\left(B^{\prime} K_{0 a}+D^{\prime} a K_{1 a}-G^{\prime} \frac{K_{0 a}}{k}\right)=0
\end{aligned}
$$

以上の結果を綜合すると，最初にあたえられた未知の常数は， $B, B^{\prime}, D, D^{\prime}, G, G^{\prime}, k$, の 7 個であり，これ に対して式 (12)，(13)，(28)，(29)，(30)，(31)，(32)07個の条件式が成立する。従つてこれらの式を連立 に解くことにより，上述の 7 個の常数を一義的に決定寸ることができる。従つてまた，これらの常数を式 (14), (15) に代入し，更に式 (17)，(18)，(23) 等を用いて，地中に生じる応力状態を知ることができる。 


\section{3. 杭の摩擦支持力}

杭の摩擦支持力は，杭周面の剪断応力によるのであるから $r=a$ に拈ける $\tau$ を求めると式 (24) より

$$
\begin{aligned}
& \tau=\frac{1}{2} \frac{m E}{m+1}\left(\frac{\partial w}{\partial r}\right)_{r=a}=\frac{1}{2} \frac{m E}{m+1} \Sigma\left[-B^{\prime} K_{1 a}-D^{\prime} a K_{0 a}\right] \sin k z \\
& =\frac{\mu \rho}{m-1} \cdot \sum_{0}^{\infty} \frac{8 l}{\pi^{2}} \frac{(-1)^{n}}{(2 n+1)^{2}} \sin \frac{2 n+1}{2} \frac{\pi}{l} z=\mu \rho \frac{1}{m-1} z
\end{aligned}
$$

彷つて杭の摩擦全支持力は

$$
T=2 \pi a \int_{0}^{l} \tau_{r=a} d z=u p \frac{1}{m-1} \frac{1}{2} l^{2} \cdot 2 \pi a
$$

即ち杭周辺の摩擦力分布は深さに比例して直線的に变化し, 従つてまた摩擦支持力は杭の長さの平方に比例し て増加する。このことは Dörr のあたえた杭の支持力公式のうちの摩擦支持力計算の根拠を妥当とするものであ る。Dörr に上れは摩擦支持力は

$$
T_{1}=\mu \rho 2 \pi a \varepsilon_{1} \frac{l^{2}}{2}
$$

但し土の内部摩擦角を $\varnothing$ とすれ标， $\varepsilon_{1}$ は $\tan ^{2}\left(\frac{\pi}{4}+\frac{\varphi}{2}\right)$ と $\tan ^{2}\left(\frac{\pi}{4}-\frac{\varphi}{2}\right)$ の中閪の值であり，一般に は $\varepsilon_{1}=1+\tan ^{2} \rho=1 / \cos ^{2} \Phi$ とし阤く成層した地盤では $\tan ^{2}\left(\frac{\pi}{4}-\frac{\phi}{2}\right)$ 又は $\cos ^{2} \Phi$ をとるとしている。著者の導 いた式 (33) 又は式 (34) のなかの 1/(m-1) はこの Dörr 式の $\varepsilon_{1}$ に相当するわけである。 は次の関係式があるとされている。即ち乾燥砂のようなるのについては2),

$$
\begin{aligned}
& m=2 / 1-\sin \varphi \\
& \therefore \frac{1}{m-1}=\frac{1-\sin \varphi}{1+\sin \varphi}=\tan ^{2}\left(\frac{\pi}{4}-\frac{\varphi}{2}\right) \text {. }
\end{aligned}
$$

即ち弛く成層した乾燥砂質の地盤では式 (34) と式 (35) は一致する。然しながら式 (34)のm悔察の土 について実測された值を用いて計算したううが正しいと思われる。このことは式の誘導には $\varnothing$ を考えていないこ とから当然と考えられる。

$m$ の実測值の一例として次のようなものがある(表-1 参 照 $)^{3)}$ 。

$1 / m=0.47$ とすれば $1 /(m-1)=0.885$ となる。式 (36)より この $m$ に相当する $\Phi$ は約 $0^{\circ} 21^{\prime}$ となる。従つて内部摩擦角よ

\begin{tabular}{|c|c|c|}
\hline 種 & 密度 $(\rho)$ & ポアソン比 $1 / m$ \\
\hline 埋 土, 表 土 & 1.5 & $0.35 \sim 0.37$ \\
\hline 粘 土 & 2.0 & $0.47 \sim 0.48$ \\
\hline 粘土混り砂磞 & 2.0 & 0.26 \\
\hline 砂 & 1.38 & 0.41 \\
\hline$F$ & 1.30 & 0.33 \\
\hline
\end{tabular}
り $m$ を求めるのは適当でないと思われる。星埜博士があたえ た杭支持力公式4)のうち摩擦支持力の項は式 (34) と同じ形式 であり，ただ $m=2$ と扔けばよい。しかしこれは理論上うなず き難いが実測のポアソン比が 0.47〜0.48 をとる場合は星埜公

表一1 土のポアソン比と密度

䃒考 砂の含水率は $6.11 \%$, 空㗂率は $36.8 \%$, 口-ムの含水率沙 $50.3 \%$ 式による值とかなり一致するものと思われる。

土の内部の粘着力の影響は $m$ に含ませて考え机ばよい。以は全て杭と土との附着力を無視して来たが，ぬ しこの附着力を考えるときはこれをレとすれはば，

$$
r=a \text { で } \tau=\mu \sigma_{r}+\nu
$$

従つて式 (31) の代りに

$$
\nu+\sum_{0}^{\infty} \mu \frac{m-1}{m-2}\left|\frac{\partial f(r)}{\partial r}\right|_{r=a}=0
$$

なる式を用いればよいことになる。

\section{4. 場所詰杭 (Pile in situ) の摩擦支持力の一計算法}

この場合は勿論 $u=0$ である。又，砂質の地艋に杭を打ちこんだ場合，最大主応力が $\overline{r t}$ の面内に生じるもの と考えられるから，砂質の性質上，塑性条件の関係から $u=0$ でなければならない。従つて式 (13), (14) から

$$
f(r)=B=D=0
$$

$z=0$ で $\tau=0$ は明らかである。更に $z=0$ で $\sigma_{z}=0$ であるためには式 (14), (15), (18), (40) より

$$
D^{\prime}=0, \quad B^{\prime}=\frac{1}{k} G^{\prime}
$$

以上の結果を整理し式 (23)，(24) により剪断応力及び半径方向の垂直応力を示すと 


$$
\begin{aligned}
& \tau=\frac{1}{2} \cdot m E \sum_{m+1}^{\infty} \sum_{0}^{\infty} G^{\prime} K_{1}\left(z \cos k z-\frac{1}{k} \sin k z\right) \\
& \sigma_{r}=\frac{1}{m-1} \rho_{z}+\frac{m E}{(m+1)(m-2)} \sum_{0}^{\infty} G^{\prime} z \sin k z \cdot K_{0}
\end{aligned}
$$

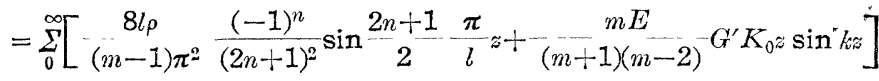

$$
\begin{aligned}
& (n=0,1,2, \cdots \cdots .00 \approx \leqq b)
\end{aligned}
$$

$r=a$ で $\tau \leqq \mu \sigma_{r}$ である。而して杭周面の或る1点に於て $\tau=\mu \sigma_{r}$ となつた場合をこの杭の摩擦支持力をあた えるるのと仮定する。この等号が杭の何れの点に生でるかは明らかでないが，杭が沈下をしようとする㭙は，そ

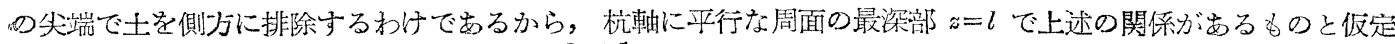
をする。そのときは式 (42),(44)より

$$
G^{\prime}=-\frac{m+1}{\operatorname{Em}(m-1)} \mu \frac{8}{\pi^{2}} \stackrel{\rho}{(m-1)} \frac{(-1)^{n}}{(2 n+1)^{2}} /\left\{\frac{K_{1 a}}{K_{0 a}} \frac{1}{(2 n+1) \pi}+\frac{\mu}{m-2}\right\}
$$

式（45）を式 (42)，(43) に代大寸ることにより 杭周面に作用吉る摩擦支持力及び側圧を求めること ができる。

一例として, $m=4,\left(\varphi=30^{\circ}\right), \mu=0.5$ として計算 した結果を図一3，4，5 に示与。

図一3は杭径 $20 \mathrm{~cm}$, 杭長 $10 \mathrm{~m}$ としたときの杭 周面の応力分布を示吉。杭徍や杭長を变化させてる これと同じような形の分布をなす。図の $\sigma_{r}$ の分布 は『一般に含水量の少ない地般では一定の深さまで 土圧は直線的に增加し，それ以上の深さでは一定の 值をとるとするのが適当である』5) という傾向に一 致し，これを説明するすのと言える。

図一4 は，杭長を $10 \mathrm{~m}$ として杭佳を変化させた ときの全摩擦支持力 $2 \pi a \int_{0}^{l} \tau_{r=a} d z$ を示す。杭径 を太くすると支持力は杭径に比例する以上に増㸝するから，杭 周の合計が同じなら細い杭を多く使用するより，太い杭を少な く用いる方が有利と思われる。但し実際上，他のいろいろの関 係から制限をうけるから，図について言えば，杭長 $10 \mathrm{~m}$ なら 直径 $30 \sim 40 \mathrm{~cm}$ が最も適当と思われる。

図一5 は杭径 $20 \mathrm{~cm}$ のとき，杭長を変化させたときの全摩 擦支持力を示す。深さとともに曲線的に堌大するが，必ずしも 深さの平方に比例しては増加しない。

\section{5. 結 言}

以上の如くして従来，比較的不明の問題の多い基礎杭の支持 カについて, 弾性学的に検討しその理論的根拠を一部明らかに することができた。基礎杭としては更に，杭尖端交持力や群杭 支持力等の問題が女るが，著者は目下これらについて研究中で ある。終りに著者は御助言を頂いた京都大学の村山及び郡雨先 生に厚く謝意を表するものである。
図-3

Stress Distributions on the Surface around a Friction-Pile

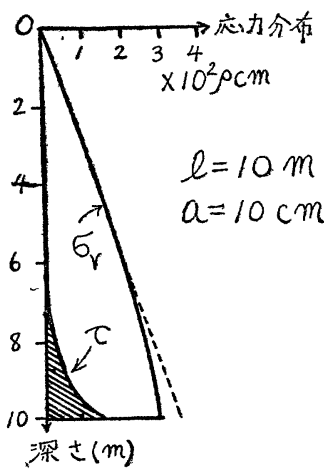

図一 $4 \quad i=10 \mathrm{~m}$

Relations between Supporting Power of a Friction-Pile and $\mathrm{Ra}$ dius of the Pile (PileLength is $10 \mathrm{~m}$ )

摩擦全支持力

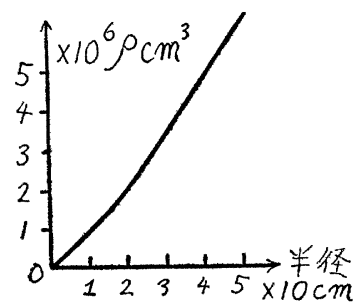

図-5 $\quad a=10 \mathrm{~cm}$

Relations between Supporting Power of a Pile by Friction and Length of the Pile (Pile-Radius is $10 \mathrm{~cm}$ )

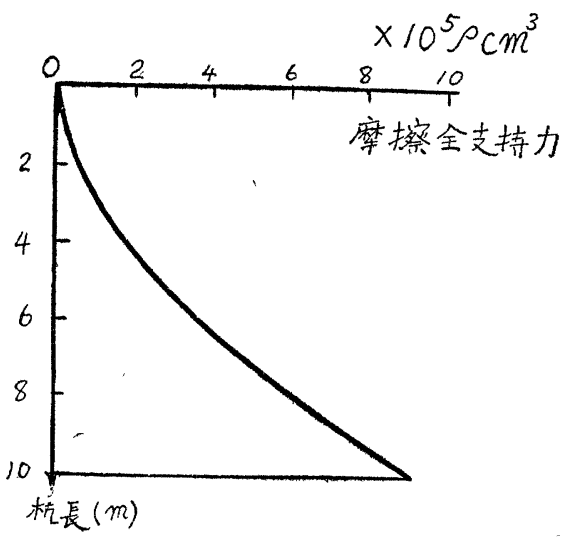

註:-1) 例兄ば木村二郎: 士桴会誌 第 17 巻 第 8 号 昭.6-8, p.717

2) 水野高明: 九大工学凅報 第 17 巻 第 1 号, p.31

3) 那须信治, 荻原尊礼, 表俊一郎: 地震研究所稪款第 14 号 昭. 11

4) 星埜 和: 建設工学 策 2 卷 第 $9 \sim 11$ 号 p.5

5) 例光ば, 原口恐次郎, 米田正交: 新稿土之杭の工学 昭.26 p.169 